\title{
EDITORIAL
}

\section{La calidad y el rol de las Revistas Científicas}

\section{El concepto de lo mejor es un resultado natural de la evolución*}

La información, los resultados y el análisis escrito en una revista científica deben ser presentados con calidad para que sea analizada, criticada y asimilada por la comunidad científica.

En 1962 la UNESCO publicó la Guía para la Redacción de artículos científicos destinados a publicación ${ }^{1}$, normas que deberían aplicarse en publicaciones científicas con la finalidad de mejorar los sistemas de información que existían. En esta Guía se menciona la originalidad de los artículos, la no-duplicación de las publicaciones, la forma de presentación de los artículos, la identificación bibliográfica (BIBLID), longitud de los resúmenes, entre otros. Desde ese entonces las normas han evolucionado para lograr mayor facilidad y claridad en la comunicación de los trabajos expuestos en las revistas. Así, también surgieron las normas ISO para publicaciones periódicas y los códigos internacionales como el ISSN (para identificar las publicaciones periódicas y facilitar las transacciones comerciales).

Con la extensión del uso de los sistemas de computo y las bases de datos, las revistas científicas pudieron ser revisadas y visualizadas por mayor numero de investigadores, logrando mayor cobertura y rapidez en la difusión de la información científica. Colocar la información en estas grandes bases de datos se conoce como indización en catálogos. Estas constituyen indiscutibles mejoras en la calidad del trabajo de difusión incremento los requerimientos y las normas para facilitar esta indización. En La edición de revistas científicas: guía de buenos usos ${ }^{2}$, publicación del Centro de Información y Documentación Científica de España, se señala que los elementos de calidad que deben estar presentes en las revistas científicas pueden ser de dos tipos uno referido a los aspectos formales como: la impresión, la normalización, información sobre el proceso de evaluación del articulo, organización y política editorial, mecanísmos de evaluación y cumplimiento de la periodicidad. En los aspectos indirectos: la naturaleza de las contribuciones, la difusión, pervivencia o prestigio histórico, apertura institucional de las contribuciones, requerimiento en las bibliotecas o como citaciones en otras publicaciones. Otros aspectos indirectos mencionados son los relacionados al contenido científico (e. g. proporción de artículos aceptados y rechazados), orientación critica de los trabajos científicos, grado de colaboración multidisciplinaria, juicio por pares (árbitros), entre otros. Se afirma por lo tanto que el cumplimiento de todos estos elementos, conocido en general como normalización, se convierte en un filtro para entrar en las mencionadas base de datos y que entrar en ellas, actualmente, es el factor fundamental para el éxito de la comunicación científica, ya que estas bases de datos se han erigido en intermediarios imprescindibles en la obtención y recuperación de información. ${ }^{3}$

todo ideal es una fe en la posibilidad misma de la perfección*

En resumen la calidad de la revista científica involucra no solo la edición y la impresión de forma clara. También es importante la adopción de un estilo adecuado de presentación, que permita la claridad y entendimiento del trabajo en el ámbito nacional e internacional. Además como ya ha sido señalado 4 la calidad de la revista científica esta ligado al tratamiento de los artículos, específicamente a la revisión por árbitros, aspecto importante en la discusión previa del artículo. Además de ajustar el artículo a los requerimientos legales, éticos, 
nacionales e internacionales recomendados para las publicaciones científicas.

Sin embargo, no hay que olvidar que la calidad de las revistas científicas esta íntimamente ligadas a lo que fueron sus orígenes: el principal medio para la presentación de los resultados de la investigación científica; para nuestro medio también es el testimonio de la producción académica local y un indicador de la institucionalización de la comunidad científica, que utiliza a la revista como un medio de exposición y crítica de su producción constituyéndose en el ejemplo más representativo de lo que significa la frase "la ciencia se nutre de la ciencia". ${ }^{5}$

Necesitamos ver en las revistas científicas el lugar más adecuado para la documentación, análisis y discusión de las investigaciones científicas nacionales. Las revistas científicas deben ser una alternativa de calidad que evite la perdida de información científica o que suele ir a los informes internos, notas informales, discusiones orales y otros medios no convencionales, que convierte a nuestra producción científica en literatura gris, ciencia oculta o periférica. Desde el año 1998 la Universidad Nacional Mayor de San Marcos, a través del Consejo Superior de Investigacio- nes ha hecho posible la edición de la Revista Peruana de Biología. Han sido publicados diez números en los cuales la rigurosidad científica y los cambios para adaptarse al logro de la perfección son conspicuos. Aunque aún falta concertar en esta mesa de trabajo a más miembros de nuestra comunidad científica ya avizoramos este logro.

\section{Editor Jefe}

* Ingenieros, J. El Hombre Mediocre.

$1 \mathrm{UNESCO} / \mathrm{NS} / 177$, que en la actualidad cuenta con la versión revisada de Anders Martinsson, Paris UNESCO, 1983

2 Román, Adelaida; et al. 2001. La edición de revistas científicas: guía de buenos usos. Madrid: Centro de Información y Documentación Científica CINDOC (CSIC), 2001.

3 Delgado, E. 1997. Incidencia de la normalización de las revistas científicas en la transferencia y evaluación de la información científica. Rev. Neurol. 25 (148): 1942-1946.

4 Cuevas, R. y M. Mestanza. 2002. Evaluación científica y el sistema de evaluación por pares. Boletín CSI 46: 4 - 5

5 Ríos, J. 2000. Normalización de revistas científicas mexicanas: campo de investigación y aportación. Bibl. Univ. Nueva Época, 3(2): 85 - 91 